\title{
El movimiento antifracking en tierras vascas: relato, movilización y disputa de la evidencia científica
}

The anti-fracking movement in The Basque Country: story, mobilization and dispute of the scientific evidence

JULEN ORBEGOZO TERRADILLOS

Universidad del País Vasco / Euskal Herriko Unibertsitatea (UPV/EHU) julen.orbegozo@ehu.eus

ION ANDOni Del Amo CASTro

Universidad del País Vasco / Euskal Herriko Unibertsitatea (UPV/EHU) ionandoni.delamo@ehu.eus

ENARA ZARRABEITIA BILBAO

Universidad del País Vasco / Euskal Herriko Unibertsitatea (UPV/EHU) enara.zarrabeitia@ehu.eus

\section{Resumen}

Este trabajo de investigación examina el movimiento de oposición al fracking en tierras vascas, estudiando la construcción del conflicto medioambiental y del discurso por parte de sus actores y el contexto en el que se desarrolló. Para ello, este estudio de caso ha empleado una metodología basada en entrevistas, y análisis del discurso y de contexto. La rápida creación, y la sólida pero dinámica organización del movimiento, junto a la profunda labor de documentación de sus portavoces, contribuyó a que se constituyera un interlocutor creíble. La combinación de lenguajes de valoración, desde la disputa de los datos científicos y económicos, hasta el desarrollo de lenguajes de valoración alternativos en base a argumentos medioambientales y de salud, no limitando su argumentario a la alarma social, llenó de legitimidad y eficacia al movimiento ante la sociedad. Las plataformas contra el fracking recurrieron a la movilización social como estrategia de presión, una movilización que fue in crescendo tanto cuantitativa como cualitativamente. El estudio, en suma, contribuye a documentar y entender mejor la historia y dinámicas de los movimientos medioambientales.

Palabras clave: Ciencia y activismo, movimientos sociales, lenguajes de valoración ambiental, acción colectiva, fracking, ecologismo, País Vasco

\begin{abstract}
This research work examines the movement of opposition to fracking in The Basque Country, studying the construction of environmental conflict and discourse by its actors and the context in which it was developed. For this, this case study has employed a methodology based on interviews, and analysis of discourse and context. The rapid creation, and the solid but dynamic organization of the movement, together with the profound documentation work of its spokespersons, contributed to the creation of a credible interlocutor. The combination of valuation languages, from the dispute of scientific and economic data, to the development of alternative valuation languages based on environmental and health arguments, not limiting their argument to social alarm, filled the movement with legitimacy and effectiveness before society. The platforms against fracking reminded social mobilization as a strategy of pressure, a mobilization that was in crescendo both
\end{abstract}


quantitatively and qualitatively. The study, in short, helps to document and better understand the history and dynamics of environmental movements.

Key words: Science and activism, social movements, environmental assessment languages, collective action, fracking, ecology, Basque Country 


\section{Introducción}

El objetivo de este trabajo de investigación consiste en describir, analizar y contextualizar los ingredientes que confluyeron en el movimiento contra el fracking ${ }^{1}$ en el País Vasco. Se trata de un estudio de caso de un movimiento ecologista y sus aliados relativamente reciente y poco estudiado. Para abordarlo se han realizado entrevistas personalizadas con impulsores y militantes del movimiento, así como con expertos en el contexto técnico, social y político de la Comunidad Autónoma del País Vasco (CAPV).

El fracking aterrizó en tierras vascas en 2011 y durante más de cuatro años se produjeron significativas movilizaciones contra la técnica, generando controversias en los principales partidos y erigiéndose en una de las cuestiones que más debate y movilización concentró en las esferas política y mediática vascas (Herce, 2014). El movimiento contra la fractura hidráulica recogió el testigo de otros fenómenos de oposición a proyectos como el de la Central Nuclear de Lemoiz, la Y vasca (Tren de Alta Velocidad), la Autovía de Leizarán, o la construcción del embalse de Itoiz.

En efecto, los conflictos ambientales han jalonado la historia reciente en tierras vascas. Algunos de ellos han dado lugar a importantes movilizaciones y han forjado el imaginario colectivo vasco. El hito más destacado lo constituye, sin duda, el conflicto en torno al proyecto de construcción de una central nuclear en la localidad vizcaína de Lemoiz. La oposición antinuclear había logrado detener los proyectos de Deba (Gipuzkoa), Ea/Ispaster (Bizkaia) y Tudela (Nafarroa), pero las obras de Lemoiz estaban en marcha y se constituyó en el símbolo de lucha antinuclear a finales de la década de 1970. El proyecto originó una oleada de protestas, recogidas de firmas, movilizaciones y festivales multitudinarios en demanda de su paralización, organizados por grupos ecologistas y de izquierda, articulados en torno a la plataforma Comisión de Defensa de una Costa Vasca no Nuclear. La paralización se produciría finalmente a raíz de la moratoria nuclear decretada por el gobierno socialista de Felipe González en 1984.

El proyecto de construcción de la denominada autovía de Leizarán, entre Nafarroa y Gipuzkoa, constituiría otro enconado conflicto ambiental a finales de la década de 1980 y principios de la de 1990. El proyecto, con graves impactos ambientales, concitó la oposición de sectores ecologistas y de la izquierda independentista, y devino en un conflicto ambiental que se convirtió en social y político, en el enconado panorama de los 90 . La coordinadora Lurraldea, que aglutinaba la oposición, esgrimió la necesidad de un proyecto alternativo, y finalmente en 1992 acordó con las instituciones la modificación del proyecto.

La construcción del proyecto de embalse en torno al pueblo navarro de Itoiz, entre los valles de Arce y Lónguida, resultó otro conflicto ambiental desde la segunda mitad de la década de 1980. La Coordinadora de Itoiz fue creada en 1985 y contó con el apoyo de

${ }^{1}$ La técnica del fracking consiste en inyectar a alta presión un fluido de fracturación para romper la roca y abrir y agrandar las fracturas con objeto de que los hidrocarburos fluyan al interior del pozo (Comisión Europea, 2014). De este modo, se consigue aprovechar los hidrocarburos no convencionales (gases no convencionales como el gas de pizarra o el gas de esquisto), que no pueden obtenerse por mera extracción (con o sin ayuda de bombeo) de una reserva subterránea (Ecyt-Ar, 2013). 
Greenpace. Las acciones opositoras en este caso combinaron la movilización con una procelosa vía judicial, al tiempo que también tuvieron lugar algunos sonados actos de sabotaje sobre las obras, que finalmente se llevaron a cabo.

La oposición al proyecto de tren de alta velocidad denominado "Y vasca" es tan larga como el propio proyecto, aunque sus movilizaciones no han llegado a ser tan multitudinarias como los anteriores conflictos ambientales. La plataforma opositora AHT Gelditu Elkarlana aglutinaría a organizaciones ecologistas, sindicales y partidos de izquierdas, así como a la antidesarrollista Asamblea antiTAV. Posteriormente, y en paralelo, la Red por un Tren Social sumaría al principal sindicato vasco, ELA, en detrimento de la Asamblea, con un planteamiento más orientado al diálogo técnico y abierto a alternativas. En 2020, la plataforma Ahora Responsabilidad ha tomado el relevo en las movilizaciones de oposición al proyecto, que acumula retrasos y sobrecostes (Hoyos, 2020).

Tal y como relata Bárcena (2000) el fenómeno más destacable del ecologismo vasco es el del localismo, dado que todo conflicto da lugar a la creación de una coordinadora o grupo "sui generis" que pretende ofrecer una respuesta particular al problema. Pero, además, la historia de los conflictos ambientales en tierras vascas ha estado impregnada también de las características de confrontación y utilización de la violencia que saturaba el escenario sociopolítico vasco. En 1979, la activista antinuclear Gladys del Estal fallecía de un disparo de la Guardia Civil durante una manifestación en Tudela (Navarra), mientras que la organización armada ETA intervenía en la mayoría de los conflictos generando tensiones dentro del movimiento ambientalista, y llegando a asesinar a trabajadores de la central de Lemoiz en 1981 y 1982, o a empresarios como Inaxio Uria en 2008, al que acusó de participar en las obras del TAV, reventando con esta acción la coordinadora AHT Gelditu Elkarlana.

La movilización contra el fracking, sin embargo, coincide en el tiempo con el inicio de un nuevo ciclo político, y nuevas innovaciones tácticas por parte de los movimientos sociales y de protesta (Letamendia, Del Amo y Diaux, 2014), así como una mayor voluntad de colaboración y construcción de alianzas (Santamaría, Arana y Del Amo, 2019) que continuamos investigando"2. Así, una de las características definitorias del movimiento de oposición al fracking respecto a otras movilizaciones precedentes es que parece desarrollar estrategias menos basadas en la confrontación y con importante apoyo social.

\section{Marco teórico}

\subsection{Medioambiente y sociedad}

El análisis de la interacción entre medioambiente y sociedad requiere un abordaje transdisciplinario. De hecho, se pueden rastrear precedentes y contribuciones desde diferentes disciplinas científicas como la Biología, la Ecología, la Sociología o la Filosofía (Caballero, 2015). De forma especial, la Ecología Política (EP) se constituye como interdisciplina integradora del abordaje socioambiental, de la interacción entre el

2 En el marco del proyecto de investigación "Nuevas solidaridades, reciprocidades y alianzas: la emergencia de espacios colaborativos de participación política y redefinición de la ciudadanía" (CSO2017-82903-R). 
medioambiente y los factores políticos, económicos y sociales.

Así, la sociedad industrial ha dado origen, desde sus comienzos, a reacciones críticas que denunciaban algunos de los efectos destructivos anejos a los procesos de urbanización e industrialización (Riechmann y Fernández, 1994). Puede rastrearse una rica tradición de pensamiento ambiental, desde la obra de Henry David Thoureau a Murray Bookchin, y eso sólo en el contexto occidental. E incluso alguna publicación mediática como Silent Spring, de la bióloga Rachel Carson (1962), sobre los efectos fisiológicos y ambientales de los pesticidas.

Esta tradición de pensamiento ambiental soporta y origina el auge del interés de las ciencias sociales por el medioambiente que se desarrolló a principios de los setenta, como respuesta al surgimiento de la atención social a los problemas medioambientales (Dunlap, 2002). El impacto de la publicación de The Limits to Growth (Meadows et al. 1972) y la crisis energética de 1973-1974, aumentaron la preocupación por los impactos sociales de la limitación de recursos. Aunque los trabajos norteamericanos adquieren gran importancia, en Europa destacan también las aportaciones de Edgar Morin (1974), y como enfatiza Manuela Caballero (2015: 54),

tanto la reflexión teórica como el análisis empírico y aplicado de la Sociología, en relación a las cuestiones ambientales, es tan antigua como la propia cuestión ambiental, es tan diversa como diversas son las culturas nacionales, y tan plurilingüe como lo es la cultura occidental a finales de los años 70.

En uno de los artículos fundacionales de la Sociología Ambiental, Catton y Dunlap (1978) criticaban la tradición durkheimiana de explicar los fenómenos sociales solo en términos de otros "hechos sociales", y el "exencionalismo" humano que suponía a las sociedades industriales exentas de las constricciones de la naturaleza. El cambio de circunstancias exigía, a su juicio, que las ciencias sociales adoptaran un paradigma ecológico o una visión del mundo que reconociera la dependencia del ecosistema de todas las sociedades humanas. La idea de unir naturaleza y sociedad, constricciones físicas y construcciones sociales, por tanto, debería ser el eje central en el abordaje de las cuestiones medioambientales por las ciencias sociales: una explicación de cómo influye la gente en su medioambiente, y cómo el medioambiente influye en la gente.

Con todo, autores como Buttel han defendido la permanencia del enfoque construccionista (Woodgate, 2002): la afirmación de que el conocimiento medioambiental no es simplemente un espejo del mundo natural es una importante observación sociológica. El propio Dunlap (2002:20) reconoce al respecto que "los análisis de las interacciones entre sociedad y el medioambiente claramente se han enriquecido (y, con frecuencia, complicado) con la mayor concienciación de los significados simbólicos y socioculturales asignados a varios aspectos del entorno que fomentan quienes mantienen una orientación constructivista".

Los trabajos desarrollados han planteado varios debates, algunos de los cuales entroncan con el tema objeto de esta investigación. Uno de los más controvertidos ha sido el papel de la ciencia occidental, objeto, por ejemplo, de la crítica ecofeminista (Yearley, 2002). Las críticas apuntan al dualismo cartesiano, o a que el proyecto práctico de la ciencia es sobre todo explotar el mundo natural más que aprender de él en su beneficio. El cuestionamiento y 
reflexión en torno al papel de la ciencia se completan también desde otros ámbitos, como la tradición de pensamiento crítico construida desde los Estudios Sociales de la Ciencia, que visibilizan cómo las investigaciones dependen de una compleja mezcla de constructos de la ciencia y la no ciencia (Latour, 1999, 2007; Law, 2004), o los Estudios Decoloniales, que interrogan también los conocimientos occidentales hegemónicos (Santos y Meneses, 2014; Santos, 2017).

La falta de ciencia, además, suele utilizarse como razón para no detener una actividad que puede ser perjudicial para el medioambiente, como ocurre en los debates respecto del fracking. Frente a ello, el Principio de Precaución respalda la adopción de medidas protectoras ante las sospechas fundadas de que ciertos productos o tecnologías puedan crear un riesgo para la salud o el medioambiente, aunque no haya todavía una prueba científica definitiva: la carga de la prueba debería recaer sobre la actividad sospechosa. De hecho, los riesgos, en muchos casos, no se han percibido o se perciben tarde (Martínez-Allier, 2009), como el caso del asbesto, el plomo en la pintura o gasolina, o los pesticidas que contaminaron las cadenas alimentarias.

En defensa de la ciencia, se argumenta que ha sido precisamente ésta la que ha alertado sobre la mayoría de los problemas medioambientales (Yearley, 2002). El riesgo derivado del desarrollo científico-tecnológico, precisamente, se habría constituido en una característica de la modernidad tardía (Beck, 2002), debido a la reflexividad y la multiplicación de opciones, y a la falta de referentes (Giddens, 1990; Giddens, 1997), que deriva en el intento de control de las opciones de que disponemos, su fracaso continuo y la toma de conciencia de ese fracaso (Bauman, 1999).
En este contexto, la (disputada) evidencia científica se sitúa en primer plano en la identificación de riesgos y en la medición de daños y evaluación de acciones punitivas (Irwin, 2002). Así, la demanda de datos científicos - y la consiguiente batalla para establecer los "datos reales" - suele ser un rasgo común en los debates entre grupos ecologistas y organismos oficiales. Debates en los que también participan empresas y grupos de presión, que condicionan el proceso de la construcción del conocimiento científico autorizado a través de la llamada corporate science o ciencia corporativa (Kirsch, 2014), tratando de disipar las dudas sobre sus actividades contaminantes y construir una "realidad única" (Law, 2011), o al menos generar controversia científica e incertidumbre al respecto de los datos generados en su contra. La producción de conocimiento científico, en suma, juega un papel fundamental en el balance de poder dentro de un conflicto ambiental (Conde, 2014; Sánchez, 2019). Ocurre también en el caso que nos ocupa, más teniendo en cuenta que se trata de una técnica relativamente novedosa.

Ante ello, grupos ecologistas como Greenpeace o Friends of the Earth se han desplazado hacia la adopción de la ciencia y el diálogo técnico, confeccionando plantillas científicas propias. Esto les ha granjeado respeto, pero con la contraprestación de la burocratización y jerarquización, o una actitud más conservadora a la hora de pronunciarse sobre asuntos que pudieran cuestionar su reputación (Yearley, 2002).

Martínez-Alier $(2009,2014)$ apunta, al tiempo, que el activismo ambiental muchas veces se convierte también en una fuente de conocimiento. Sería lo que se denomina ciencia posnormal, basada en la evaluación ampliada a los no expertos oficiales, lo cual lleva a métodos participativos de resolución de 
conflictos y hacia la "democracia deliberativa", y entroncaría con metodologías de Investigación de Acción Participativa. A menudo, añade Martínez-Alier (2009), la gente local afectada por los impactos aprende también el vocabulario que necesita.

Así, junto con los científicos, coproducen conocimiento nuevo y alternativo que brinda a las organizaciones locales visibilidad y legitimidad, información sobre cómo protegerse de los impactos, y les permite participar en el activismo práctico, desafiando la incertidumbre fabricada y otra información producida por el Estado o empresas, la corporate science. Se trata de lo que Marta Conde (2014) denomina Activism Mobilizing Science, y Luis Sánchez Vázquez (2019) "una nueva ciencia de resistencia". De tal forma que, cuando los conocimientos científicos dominantes se utilizan bajo una lente (auto)crítica y en diálogo con otros conocimientos alternativos o subalternos dentro de la denominada "ecología de saberes", podemos afirmar que dicho uso del conocimiento científico es contra-hegemónico (Sánchez, 2019; Santos, 2017). Lo veremos en el caso que nos ocupa, donde la formación y la información por parte de las plataformas contrarias al fracking constituye un aspecto central de su estrategia.

En cualquier caso, el concepto más polémico, y que condensa las diferentes perspectivas teóricas, ha sido el desarrollo sostenible. En 1987 el informe Brundtland, fruto de la Comisión Mundial de Medio Ambiente y Desarrollo de Naciones Unidas, tratando de dar respuesta al difícil matrimonio entre desarrollismo y ambientalismo, estableció la que sería definición canónica: aquel desarrollo que satisface las necesidades del presente sin comprometer la capacidad de las generaciones futuras para satisfacer sus propias necesidades.

Wolfgang Sachs (2002) distingue tres discursos en torno a tal concepto, según su valoración del desarrollo y la manera en que relacionan la ecología con la justicia. El primero entronca con las teorías de la modernización ecológica ${ }^{3}$ : la competitividad empuja a una mayor eficiencia, especialmente energética, estimulada en base a ecoimpuestos, internalización de costes, mercados de emisiones, o nichos de mercado "verdes". En el segundo discurso, el planeta en su conjunto se revela como escenario del ajuste medioambiental; aquí cabe situar a la comunidad científica, o las grandes organizaciones ecologistas. El tercer discurso dirige la crítica al concepto de desarrollo, considerado una fuerza de descapacitación de las comunidades del sur, una fuerza reductora del bienestar en el norte, y un elemento medioambientalmente perjudicial en ambos casos, y remite a conceptos de suficiencia y autolimitación, a que las sociedades del norte reduzcan su huella ecológica, conectando con las teorías del decrecimiento (Demaria,

${ }^{3}$ La modernización ecológica (Spaargaren y Mol 1991; Janicke, 1986; Mol, 2002) es una propuesta que pretende aunar crecimiento y medio ambiente. Entendida como teoría del cambio social, se fundamenta en la idea de que crecimiento y medioambiente, lejos de resultar incompatibles, se estimulan mutuamente de forma positiva. Plantea como respuesta a la crisis ambiental una mayor modernización de las instituciones existentes en la sociedad industrial y una reestructuración de los procesos de producción y consumo. En este sentido identifica la ciencia moderna y la tecnología como instituciones centrales para la reforma ecológica, y no como las responsables primarias de la degradación social y ecológica (Caballero, 2015). 
Schneider, Sekulova y Martínez-Alier, 2013; García, 2004; García, 2006; Taibo, 2014).

Las tres visiones, y en especial la confrontación entre la primera (con el fracking presentado como "salida" tecnológica al agotamiento de los combustibles fósiles) y las otras dos (la necesidad de transición energética), constituyen los discursos en torno a los cuales se vertebrarán los debates en el caso que nos ocupa.

En cualquier caso, muchas de las nuevas visiones del cambio social discuten ya el descenso posterior a la era del desarrollo, la fase de decrecimiento que se avecina. En ese debate, la principal divisoria separa a quienes conectan el decrecimiento con la continuidad del bienestar (una "cuesta abajo próspera") de quienes lo asocian a un colapso completo y catastrófico de la civilización (García, 2006). El excepcionalismo humano, la especificidad de la cultura, aparece de nuevo como uno de los elementos esenciales en la divisoria: los "optimistas" ven el presente como una encrucijada en la que todavía es posible elegir, mientras que la fracción pesimista invoca el determinismo físico o genético para anunciar el inevitable colapso (García, 2006).

Joseba Azkarraga (2017) sitúa en la acción colectiva una de las claves para una transición ordenada. A su juicio, disponemos ya de marcos teóricos potentes, de nuevas propuestas político-económicas, movimientos sociales como los Transition Towns, por la soberanía alimentaria, el ecofeminismo o el decrecimiento, además de numerosas experiencias de medidas políticas concretas. La clave estaría en pasar de esas pequeñas rupturas y resistencias a construir mayorías sociales y hegemonía sociocultural. En ese sentido el presente caso de estudio puede proporcionar también alguna clave.

\subsection{Medioambiente en movimiento}

Ponerse en contra del status quo, de normas y leyes, desobedecer a los que ejercen el poder y reclamar la justicia, estas acciones no solo han sido parte importante de nuestra historia sino todo un arte, sin el cual difícilmente podemos imaginarnos el progreso humano (LópezMartínez, 2016). Al igual que la literatura al respecto, los movimientos medioambientales han adquirido una notable relevancia social desde la década de 1960, en el marco de la emergencia de los denominados nuevos movimientos sociales (Offe, 1996).

Los trabajos que tratan de comprender este auge dibujan tres perspectivas principales (Buttel, 2002). La tradición de Dunlap (2002) y sus colegas, por ejemplo, plantea que el desarrollo del ambientalismo, y del "nuevo paradigma ecológico", es una respuesta social a las realidades biofísicas de la destrucción medioambiental y al conocimiento científico de ello. Conocida es, por otra parte, la tesis de Inglehart (1977) acerca del desarrollo de valores posmateriales (como el respeto a la naturaleza y el interés por la calidad de vida) en las sociedades en las que se han satisfecho las necesidades materiales básicas, si bien al tiempo existen numerosos estudios que contradicen sus predicciones (Caballero, 2017; Grønhøj y Thøgersen, 2009). La tercera orientación apunta a la desorganización institucional asociada a la desintegración del fordismo, que habría socavado las reservas tradicionales de significado social, y debilitado los vehículos de agregación de intereses como partidos políticos y asociaciones; los movimientos ecologistas habrían llenado estos vacíos.

Cada una de las perspectivas tiene sus puntos fuertes y débiles. Buttel (2002) plantea una serie de características centrales de los 
movimientos ecologistas que, en todo caso, deben ser explicadas:

1. La discontinuidad en la intensidad del movimiento, que sugiere que los factores biofísicos (y científicos) no representan un papel predominante.

2. Las expresiones del ecologismo en países de la periferia ponen en duda que sea fundamentalmente un fenómeno de países ricos y clases sociales materialmente satisfechas (Martínez-Alier, 2009; Temper, Demaria, Scheidel, et al., 2018).

3. La existencia del anti-ambientalismo, que en ocasiones compite como fuerza política.

4. La enorme diversidad interna del ambientalismo organizado, en cuanto a alineamientos de clase, reivindicaciones, metas e ideologías, en una coexistencia precaria.

5. Que el ambientalismo es en buena parte un producto social: algunas expresiones que hoy consideramos como tales no lo habrían sido hace décadas.

6. Es necesario distinguir entre el apoyo público al movimiento (que tiende a ser general, pero superficial y transitorio) y la participación en el movimiento (menos numerosa pero más estable y procedente de estratos políticamente eficaces y/o cultos de la sociedad civil).

Como en el estudio de cualquier movimiento social, además, deberían de tenerse en cuenta o combinarse varios enfoques teóricos, como el de la movilización de recursos y su énfasis en el análisis de las organizaciones y los recursos de que disponen, los enfoques europeos de los nuevos movimientos sociales, que acentúan los proyectos históricos, las contradicciones estructurales y la formación de identidades e idealidades colectivas, así como la estructura de oportunidades políticas, el contexto en que nacen y operan los movimientos. A ello puede añadirse las reflexiones en torno a los cambios recientes observados en el ciclo de movilizaciones de la última década (Del Amo y Letamendia, 2020).

Respecto a los movimientos ambientalistas, Riechmann y Fernández (1994) distinguen entre, por un lado, conservacionismo o proteccionismo, que sería el movimiento de protección de la naturaleza, paisajes y especies vivas, de bajo perfil político y que toma cuerpo en el tejido de asociaciones y grupos de presión; su peligro sería la miopía, centrarse en los efectos y en lo puntual en lugar de considerar también las causas y los contextos globales. Por otro lado, el ambientalismo sería aquella actividad y aquellos movimientos sociales que luchan por una mejor calidad de vida para los seres humanos, desde un punto de vista antropocéntrico; el peligro de miopía en este caso supondría ignorar todo lo no humano. El moderno ecologismo, ecología política, o ecología social, por último, se constituye aboliendo la separación entre sociedad y naturaleza; activo desde los años setenta y radicalizado sobre todo por la lucha antinuclear, desea restructurar la totalidad de la vida económica, social y política y tiende, por tanto, a ser un movimiento antisistema (anticapitalista, ecofeminista y revolucionario) (Riechmann y Fernández, 1994; Riechmann, 2015).

Manuel Castells (1997), por su parte, recurre a la caracterización que hace Alain Touraine de los movimientos sociales para diferenciar cinco tipos principales de movimientos ecologistas, según se han manifestado en las prácticas observadas en las dos últimas décadas (ver tabla 1), y que recoge y desarrolla también las precisiones anteriores. 
TABLA 1. TIPOLOGÍA DE LOS MOVIMIENTOS ECOLOGISTAS (FUENTE: ELABORACIÓN PROPIAA PARTIR DE CASTELLS, 1997: 137)

TIPOLOGÍA DE LOS MOVIMIENTOS ECOLOGISTAS

\begin{tabular}{llll}
\hline \multicolumn{1}{c}{ Tipo (ejemplo) } & \multicolumn{1}{c}{ Identidad } & \multicolumn{1}{c}{ Adversario } & \multicolumn{1}{c}{ Objetivo } \\
\hline $\begin{array}{l}\text { Conservación de la naturaleza } \\
\text { (Grupo de los Diez, EE.UU.) }\end{array}$ & $\begin{array}{l}\text { Amantes de la } \\
\text { naturaleza }\end{array}$ & $\begin{array}{l}\text { Desarrollo } \\
\text { incontrolado }\end{array}$ & Naturaleza original \\
\hline $\begin{array}{l}\text { Defensa del espacio propio } \\
\text { (Efecto NIMBY) }\end{array}$ & Comunidad local & Contaminadores & Calidad de vida/salud \\
\hline $\begin{array}{l}\text { Contracultura, ecología } \\
\text { profunda (Earth First!, } \\
\text { ecofeminismo) }\end{array}$ & El yo verde & $\begin{array}{l}\text { Industrialismo, } \\
\text { tecnocracia } \\
\text { patriarcado }\end{array}$ & Ecotopía \\
\hline $\begin{array}{l}\text { Salvar al planeta (Greenpeace) } \\
\text { Ecoguerreros } \\
\text { internacionalistas }\end{array}$ & $\begin{array}{l}\text { Desarrollo global } \\
\text { incontrolado }\end{array}$ & Sostenibilidad \\
\hline Política verde (Die Grünen) & $\begin{array}{l}\text { Ciudadanos } \\
\text { concienciados }\end{array}$ & Establishment político & Contrapoder \\
\hline
\end{tabular}

Martínez-Alier (2009: 31) sintetiza tres corrientes principales de preocupación y activismo ambientales, con puntos de contacto y desacuerdo entre ellas, pudiendo un mismo movimiento u organización pertenecer a más de una:

- El "culto a lo silvestre", preocupado por la preservación de la naturaleza silvestre, pero sin decir nada sobre la industria o la urbanización, indiferente $\mathrm{u}$ opuesto al crecimiento poblacional, respaldado científicamente por la biología de la conservación.

- El "evangelio de la ecoeficiencia", preocupado por el manejo sustentable o "uso prudente" de los recursos naturales y por el control de la contaminación no sólo en contextos industriales sino en la agricultura, la pesca y la silvicultura, descansando en la creencia de que las nuevas tecnologías y la "internalización de las externalidades" son instrumentos decisivos de la modernización ecológica. Está respaldado por la ecología industrial y la economía ambiental.

- El movimiento por la justicia ambiental, el ecologismo popular, el ecologismo de los pobres, nacidos de los conflictos ambientales a nivel local, regional, nacional y global causados por el crecimiento económico y la desigualdad social. Ejemplos son los conflictos por el uso del agua, el acceso a los bosques, sobre las cargas de contaminación y el comercio ecológicamente desigual, que están siendo estudiados por la Ecología Política. Los actores de tales conflictos muchas veces no utilizan un lenguaje ambiental, y ésta es una de las razones por la cual esta tercera corriente del ecologismo no se identificó hasta los años ochenta.

La movilización de las comunidades locales en defensa de su espacio, contra la intrusión de los usos indeseables, constituye la forma de acción ecologista de desarrollo más rápido y la que quizás enlaza de forma más directa las preocupaciones inmediatas de la gente con los temas más amplios del deterioro medioambiental, como ocurre en el caso de estudio. Aunque el movimiento es local, no es necesariamente localista, ya que suele afirmar el derecho de los residentes a la calidad de vida en oposición a los intereses de las empresas o burocracias (Castells, 1997). 
Los lenguajes de valoración resultan también un elemento importante en los conflictos medioambientales (Martínez-Allier, 2009). Frecuentemente resultan ajenos al mercado (y también a los mercados ficticios): el valor ecológico de los ecosistemas, el respeto por lo sagrado, la urgencia del sustento vital, la dignidad de la vida humana, la demanda de seguridad ambiental, la necesidad de seguridad alimentaria, los derechos a los territorios indígenas, el valor estético de los paisajes, el valor de la cultura propia, la injusticia de exceder el espacio ambiental de cada uno, la injusticia del sistema de castas y el valor de los derechos humanos.

La lógica legitimada y el lenguaje de valoración resultan una cuestión de poder político, y se convierten también, por tanto, en terreno de disputa, al igual que la evidencia científica. Los diferentes actores de los conflictos ecológicos ponen en duda y desafían los lenguajes de valoración de otros apelando a distintos lenguajes dentro de su amplio repertorio cultural. A esta construcción del discurso prestaremos especial atención en el caso del movimiento anti-fracking.

\subsection{Situación global del fracking y los movimientos de oposición}

Hoy fracking es un término habitual en los medios de comunicación: a mucha gente esta palabra le es familiar, aun pudiendo no tener una idea precisa de en qué consiste (MartínSosa, 2015). Ello se debe, en gran medida, a los movimientos que se han articulado en respuesta a esta técnica.

Así como la técnica del fracking está en proceso expansivo y se intenta abrir paso por el mundo, se puede decir que ello está provocando una reacción contraria directamente proporcional. El relato de lo que está sucediendo en aquellos lugares donde se ha fracturado ha provocado reacciones en diferentes ámbitos, desde activistas de distinto signo hasta Estados que promulgan prohibiciones.

Las metas de estos movimientos varían desde el deseo de regular la fracturación hidráulica para hacerla segura (o más segura) hasta el deseo de prohibirla por completo. Las estrategias y tácticas de las organizaciones involucradas varían, pero han sido, hasta tiempos recientes, principalmente grupos locales intentando influenciar procesos políticos locales.

De vital importancia ha resultado la operativa de los movimientos antifracking basada en eficientes campañas. Estas campañas se fundamentan en cuatro ejes: la movilización social de base, las redes sociales e internet (webs antifracking, Facebook, Twitter, etc.), la acción directa, y el trabajo en red o descentralizado (Wood, 2012). Un análisis de las distintas campañas que ha habido alrededor del mundo puede ayudar a comprender mejor la situación actual.

En la actualidad se emplea la técnica del fracking en varios territorios y con distinta intensidad. Sin embargo, el número de países que cuentan con explotaciones comerciales es escaso: Estados Unidos, Canadá, México y China, principalmente (Ayllon, 2014). No obstante, los Estados Unidos, además de ser pioneros en el desarrollo de la tecnología relacionada con la fractura hidráulica, también lo son en el uso de esta práctica para explotar sus hidrocarburos. Según datos de la Agencia de Energía estadounidense, la producción de gas pizarra ha pasado de suponer el 1,4\% del suministro total de gas en 1990 , al $14,3 \%$ en 2009, pudiendo alcanzar un $24 \%$ para 2035 (Urresti y Marcellesi, 2012).

Institucionalmente, la situación es desigual: existen Estados que apoyan fervientemente el fracking, y otros que han 
aprobado leyes en contra, o en los que existen moratorias. Más numerosas aún son las prohibiciones locales en pueblos, ciudades, o condados. Diversas asociaciones mantienen contra el fracking intensas iniciativas como manifestaciones, campañas informativas, recogidas de firmas, peticiones a las autoridades, batallas en los tribunales, así como acciones directas como el bloqueo de accesos a pozos o zonas de perforación y sabotajes de instalaciones. Tal despliegue de acciones deja constancia de la compleja situación social, política y comercial asociada a la explotación de gas no convencional en los Estados Unidos.

El movimiento crítico americano, que después influyó en la conciencia de la sociedad europea, ganó popularidad con el apoyo del mundo de la cultura. Iniciativas como Artists Against fracking o las dos partes de la película Gasland contribuyeron a difundir en todo el mundo el problema del fracking. La propia industria impulsora de la fractura hidráulica encargó un análisis para describir "El movimiento global contra el fracking" (Wood, 2012) donde se reconoce el hecho de que la película influyó efectivamente en la regulación del fracking en países como Francia.

En Europa la llegada del fracking ha sido una especie de tsunami, que ha provocado una oleada de respuestas (Martin-Sosa, 2015). Los defensores del gas no convencional presentaron el auge y el esplendor de esta técnica en los Estados Unidos como una historia de éxito sin precedentes, que Europa debía emular. Sin embargo, además de unas reservas mucho menores, Europa presenta diferencias geológicas, geográficas e hidrológicas, entre otros factores (Flues, 2013). Además, a ello se suma, en cierta forma, la oposición pública que surge en algunos lugares donde se pretende recurrir a esta técnica.

En lo que respecta a la posición de los Estados miembros de la Unión Europea, la respuesta ha sido dispar. Algunos se muestran favorables a esta técnica y han concedido autorizaciones de exploración o investigación con vistas a una futura explotación, como es el caso de Polonia, Reino Unido, Rumanía, Portugal, Estonia, Dinamarca, Hungría, Suecia, Países Bajos y España (Ayllon, 2014; Sánchez, 2014). Al contrario, varios países han respondido con moratorias, prohibiciones de hecho o regulaciones ambientales más severas, como es el caso, de Francia, Bulgaria, Italia, Alemania, la República Checa y Luxemburgo (Cingotti, 2014). Asimismo, a pesar de que muchos Estados se muestran favorables a la técnica, también existen prohibiciones locales, como en el caso de España. Con todo, también en este caso se observa la compleja situación tanto social, como política y comercial.

\subsection{Fracking en el País Vasco}

A partir de 1940 Araba (una de las tres provincias de la Comunidad Autónoma del País Vasco, CAPV en adelante) empieza a ser un territorio importante de prospección. Urresti (2012) habla de que se han enumerado alrededor de 60 sondeos, pero advierte de que existen más. 
Sin embargo, no es hasta finales del año 2011 cuando se empieza a hablar de la técnica del fracking. A mediados de octubre de 2011 el en aquel entonces Lehendakari Patxi López (PSE-EE), en un viaje al campo de extracción de gas natural no convencional que la compañía Devon Energy Corporation tiene en Dallas (Texas, EEUU) ${ }^{4}$, anunció una gran apuesta por la extracción de hidrocarburos mediante fractura hidráulica en la CAPV como solución a su dependencia energética. Comenzó entonces un goteo de información que fue preocupando a cada vez más gente: la técnica necesaria para autoabastecerse, sus riesgos medioambientales y para la salud humana, y el hecho de que ese supuesto "descubrimiento" era conocido desde hacías décadas (Fracking Ez Araba, 2012).

Fue en ese contexto en el que varios grupos ecologistas, asociaciones, personas a título individual, partidos políticos, incluso algunos periodistas empiezan a lanzar voces que cuestionan la técnica. El objetivo era unirse $\mathrm{y}$ coordinarse para lograr fuerza $\mathrm{y}$ afianzar una nueva lucha en defensa del territorio (Fracking Ez Araba, 2012). Nace la plataforma "Fracking Ez Araba", que constituirá el germen o matriz de donde brotarán otros grupos de activistas organizados en los territorios vascos 5 .

\section{Metodología}

Este trabajo de investigación enfrenta las siguientes preguntas: ¿Cómo se desarrolló la lucha ciudadana contra el fracking en la CAPV? ¿Qué elementos interactuaron? ¿Cómo se construyen el conflicto ambiental y el discurso por parte de los movimientos ecologistas?

Abordamos, en suma, un estudio de caso (Heras et al., 2012) y el enfoque constructivista defendido por autores como Buttel (2002) parece el más adecuado, puesto que resulta determinante la construcción social, comunicativa y discursiva del conflicto ambiental. La metodología para el estudio empírico, por tanto, será principalmente de carácter cualitativo, que dé cuenta de la representación dinámica de la realidad realizada por los sujetos sociales, en el sentido defendido por autores como Luis Enrique Alonso (2013: 212):

La interpretación sociológica de los discursos, no es, por tanto, un análisis de contenido — tomado este como suma de los significados prefigurados de las palabras que componen el texto-, ni un análisis formal —se realice en el plano sintáctico, morfológico, estilístico, fónico, o semántico-, sino un análisis contextual, donde los argumentos toman sentido en relación con los actores que los enuncian,

\footnotetext{
4 En octubre de 2011, aprovechando un viaje oficial a Texas (una de las cunas de la fractura hidráulica), el entonces Lehendakari Patxi López aseguró que cerca de Vitoria existe un descomunal yacimiento de gas a 2.000 metros de profundidad que podría satisfacer las necesidades energéticas de la CAPV durante 60 años. Un goloso hallazgo al que, aseguró, nadie se había planteado llegar hasta ese momento ante la falta de una técnica adecuada. El Gobierno Vasco se alió con dos empresas norteamericanas e inició un proceso burocrático previo (El Correo, 19/12/2014).

5 Citando al "movimiento contra el fracking" se hará referencia al conjunto de todas las plataformas contra el fracking de la CAPV.
} 
enmarcados en un conjunto de fuerzas sociales en conflicto que los originan. El hacer interpretativo, es un querer saber sobre el hacer de los discursos, esto es, una práctica de atribución de sentido de los discursos centrada sobre lo que los discursos hacen en sociedad.

Se ha optado, por tanto, por este diseño metodológico debido a su idoneidad para el análisis de los complejos procesos implicados en las luchas ambientales. Así, el estudio de caso permite analizar un fenómeno actual en su entorno físico y de situación real, utilizando para ello múltiples fuentes de evidencia, cuantitativas $\mathrm{y} / \mathrm{o}$ cualitativas de forma simultánea (Yin, 1998).

Así, el objetivo principal de este trabajo es obtener una descripción detallada del movimiento contra el fracking en tierras vascas y sus factores de éxito. Específicamente, se considera que para entender el fenómeno en su conjunto hay que fijarse en los principales elementos que contextualizan esta lucha. Se detectan tres apartados de investigación, señalándo su análisis como objetivos subsidiarios de este trabajo:

Objetivo 1: Extraer los principales hitos $\mathrm{y}$ hechos transversales que jalonan el camino de esta lucha ciudadana. Hitos, entendidos como eventos con fecha concreta; y hechos transversales, entendidos como elementos que acompañan durante cierto recorrido al movimiento contra el fracking ${ }^{6}$.

Objetivo 2: Obtener la caracterización discursiva (relato) que el propio movimiento contra el fracking contruye en torno a agentes, actores o elementos que interactuaron en esta problemática; esto es, la construcción del conflicto medioambiental que realiza el movimiento.

Objetivo 3. Compilar argumentos, estrategias y lenguajes de valoración que movilizan las plataformas que se oponían al fracking; su evolución y trascendencia en la opinión pública y la opinión publicada.

Así, en primer lugar, se ha llevado a cabo una revisión multidisciplinar de la literatura sobre el ámbito de estudio, tanto trabajos académicos como estudios técnicos. En segundo lugar, se han realizado diez entrevistas en profundidad semiestructuradas a diferentes agentes relacionados con el movimiento contra el fracking en tierras vascas. La muestra se ha dividido en cuatro subgrupos: activistas, investigadores, periodistas y cargos electos, todos ellos en contacto directo con el fenómeno social, y con el objetivo de tener una perspectiva abierta y multidisciplinar del movimiento. Todos los informantes ofrecen matices diferenciados pese a, en ciertos casos, pertenecer al mismo subgrupo (tabla 2). Si cabe, merece puntualizar que el apartado de activistas que agrupa a cuatro informantes de diversas plataformas también recoge en su seno diferencias sustanciales entre las fuentes, como, por ejemplo, la representatividad e importancia (mayor o menor) de la plataforma en la que trabajan o la zona en la que deciden involucrarse.

El proceso de muestreo ha seguido un método de muestreo teórico (Heras et al., 2013). El diseño no trata de recoger el universo discursivo, tan sólo los discursos de los representantes inmersos en el conflicto ecológico y social. La selección de los entrevistados, pues, ha sido deliberadamente no aleatoria y dirigida a entrevistar diferentes agentes relevantes a la hora de analizar el

6 Por ejemplo, una manifestación es un hito con fecha concreta, y el empleo del merchandising (camisetas, banderolas, etc.) es una circunstancia transversal que se alarga en el tiempo. 
movimiento antifracking de la CAPV. Para identificarlos, por una parte, se han seleccionado las figuras más notorias o visibles en los medios de comunicación, y por otra, a modo bola de nieve, los candidatos seleccionados han sugerido a otros que son de interés. La duración de las entrevistas, realizadas entre marzo y junio de 2016 , ha sido entre dos y tres horas.

\section{TABLA 2. PERFIL DE ENTREVISTADOS (FUENTE: ELABORACIÓN PROPIA)}

\begin{tabular}{|c|c|c|c|}
\hline $\begin{array}{l}\text { Entrevi } \\
\text { sta }\end{array}$ & & Perfil & $\begin{array}{c}\text { Breve descripción del entrevistado y su involucración en } \\
\text { el } \\
\text { movimiento contra el fracking }\end{array}$ \\
\hline A1 & \multirow{4}{*}{$\begin{array}{l}\text { Acti } \\
\text { vist } \\
\text { as }\end{array}$} & $\begin{array}{l}\text { Portavoz y activista de } \\
\text { la plataforma "Fracking } \\
\text { Ez Araba" }\end{array}$ & $\begin{array}{l}\text { Participa en la génesis del movimiento. Se convierte en } \\
\text { portavoz y en la cara más visible de los antifracking. }\end{array}$ \\
\hline $\mathrm{A} 2$ & & $\begin{array}{l}\text { Activista de la } \\
\text { plataforma "Fracking Ez } \\
\text { Araba". }\end{array}$ & Activista del movimiento desde sus inicios. \\
\hline A3 & & $\begin{array}{l}\text { Activista de la } \\
\text { plataforma "Fracking Ez } \\
\text { Aiaraldea" }\end{array}$ & Activista del movimiento en Laudio (Araba). \\
\hline A4 & & $\begin{array}{l}\text { Activista de la } \\
\text { plataforma "Fracking Ez } \\
\text { Durangaldea" }\end{array}$ & Activista del movimiento en Durango (Bizkaia). \\
\hline I5 & \multirow{2}{*}{$\begin{array}{l}\text { Inve } \\
\text { stig } \\
\text { ador } \\
\text { es }\end{array}$} & $\begin{array}{l}\text { Doctora en ciencias } \\
\text { ambientales por la UAB } \\
\text { e investigadora en } \\
\text { conflictos socio- } \\
\text { ambientales }\end{array}$ & $\begin{array}{l}\text { Investigadora con gran experiencia en conflictos socio- } \\
\text { ambientales y movimientos ecologistas en torno a la } \\
\text { minería. }\end{array}$ \\
\hline I6 & & $\begin{array}{l}\text { Profesor universitario e } \\
\text { investigador }\end{array}$ & $\begin{array}{l}\text { Profesor universitario e investigador en energías } \\
\text { renovables. Miembro de la Comisión Ejecutiva Federal de } \\
\text { Equo. }\end{array}$ \\
\hline P7 & \multirow{2}{*}{$\begin{array}{c}\text { Peri } \\
\text { odis } \\
\text { tas }\end{array}$} & $\begin{array}{l}\text { Periodista de } \\
\text { información general }\end{array}$ & $\begin{array}{l}\text { Periodista especializado en temas medioambientales de un } \\
\text { medio de comunicación de información general en la } \\
\text { CAPV. }\end{array}$ \\
\hline P8 & & $\begin{array}{l}\text { Periodista } \\
\text { medioambiental } \\
\text { especializado en } \\
\text { fracking }\end{array}$ & $\begin{array}{l}\text { Periodista especializado en fracking. Ha publicado varios } \\
\text { trabajos relacionados con la fractura hidráulica. }\end{array}$ \\
\hline C9 & \multirow{2}{*}{$\begin{array}{l}\text { Car } \\
\text { gos } \\
\text { elec } \\
\text { tos }\end{array}$} & Parlamentario & $\begin{array}{l}\text { Parlamentario en el Parlamento Vasco cuyo grupo } \\
\text { parlamentario rechaza desde el inicio el empleo del } \\
\text { fracking en la CAPV. }\end{array}$ \\
\hline $\mathrm{C} 10$ & & Parlamentario & $\begin{array}{l}\text { Parlamentaria en el Parlamento Vasco cuyo grupo } \\
\text { parlamentario partiendo de posturas favorables a la técnica, } \\
\text { acaba rechazándola. }\end{array}$ \\
\hline
\end{tabular}




\section{Resultados}

\subsection{Hitos y hechos principales}

En cuanto a los hitos y hechos transversales, se exponen a continuación dos listas con las respuestas obtenidas. En la primera de ellas se citan hechos con fecha concreta (tabla 3), y en la segunda hechos que acompañan la lucha transversalmente a lo largo del tiempo (tabla 4). Gracias a la información obtenida se elaboran ambas listas, obteniendo una cronología de la lucha ciudadana contra el fracking en la CAPV.

\section{TABLA 3. EVENTOS CONCRETOS MÁS RELEVANTES EN LA LUCHA CIUDADANA CONTRA EL} FRACKING EN LA CAPV (FUENTE: ELABORACIÓN PROPIA)

\begin{tabular}{|c|}
\hline $\begin{array}{l}\text { Anuncio del Gobierno Vasco (Lehendakari Patxi López) en EE.UU de la apuesta por la } \\
\text { extracción de hidrocarburos mediante fracking en la CAPV (Se trata de un anuncio institucional en } \\
\text { un contexto de crisis comunicativa, dejando en el aire importantes cuestiones técnicas) [octubre, 2011] }\end{array}$ \\
\hline $\begin{array}{l}\text { Comienzos del movimiento contra el fracking (Responde a una preocupación social espontánea e } \\
\text { inmediatamente, y adquiere una identidad transversal y plural) [noviembre, 2011] }\end{array}$ \\
\hline $\begin{array}{l}\text { Presentación pública de la plataforma "Fracking Ez Araba" (Punta de lanza del movimiento contra } \\
\text { el fracking en la CAPV, se constituye como interlocutor válido para periodistas, partidos políticos y } \\
\text { sociedad en general) [diciembre, 2011] }\end{array}$ \\
\hline $\begin{array}{l}\text { Campaña de recogida y presentación de alegaciones al permiso de exploración Enara-4 (Toma } \\
\text { cuerpo el trabajo en red del movimiento y la apuesta por la movilización social) [enero, 2012] }\end{array}$ \\
\hline $\begin{array}{l}\text { Jornadas y debates sobre el fracking y el contexto energético: primeros careos públicos entre } \\
\text { favorables y contrarios a la técnica. (En las jornadas de Villa Suso, Gasteiz, organizadas por tres } \\
\text { instituciones públicas, se invitaron a } 25 \text { expertos internacionales, la mayoría, de claro sesgo favorable al } \\
\text { fracking. Sin embargo, trascendieron públicamente más las intervenciones realizadas por el movimiento } \\
\text { contra el fracking) [Abril 2012] }\end{array}$ \\
\hline $\begin{array}{l}\text { Manifestación en Gasteiz (Se reúnen } 13.000 \text { personas en una movilización histórica a nivel } \\
\text { internacional) [octubre, 2012] }\end{array}$ \\
\hline $\begin{array}{l}\text { Acción directa contra trabajos sobre el terreno de investigación geofísica (Los trabajos de la } \\
\text { empresa pública SESHA en Orozko, Bizkaia, se interpretan como un avance del fracking en la zona. } \\
\text { Los vecinos responden con sabotajes. Estas acciones recibieron apoyo social en la zona afectada) } \\
\text { [junio, 2013] }\end{array}$ \\
\hline $\begin{array}{l}\text { Primera consulta a nivel estatal sobre el fracking: Kuartango (El evento recibe un eco mediático } \\
\text { remarcable. Se interpreta como un triunfo de la opinión pública contra el fracking, contando con el } \\
\text { apoyo de una institución local gobernada por un partido, PNV, que a priori no se opone al fracking) } \\
\text { [octubre, 2013] }\end{array}$ \\
\hline $\begin{array}{l}\text { Frackanpada. Acampada internacional contra el fracking (El movimiento vasco contra el fracking } \\
\text { se globaliza, y organiza sus propias jornadas internacionales de debate, con expertos a nivel mundial) } \\
\text { [julio, 2015] }\end{array}$ \\
\hline
\end{tabular}

TABLA 4. FORMAS DE LUCHA PROLONGADA MÁS RELEVANTES EN LA LUCHA CIUDADANA CONTRA EL FRACKING EN LA CAPV DESDE 2012 A 2015 (FUENTE: ELABORACIÓN PROPIA)

Trabajo de sensibilización ciudadana (Se responde así con gran cercanía y con información técnica a una preocupación social creada por el anuncio de la extracción de hidrocarburos mediante fracking)

Elaboración de un dossier técnico sobre el fracking (La apuesta divulgativa se cristaliza, realizando un trabajo técnico y de investigación con documentación, dirigido a la divulgación, pero también a la formación interna)

Movilizaciones a pie de calle (Concentraciones, marchas, etc.) 
Utilización de internet y redes sociales (Sirven para trabajar en red con otros movimientos. Suponen otras formas de comunicación más allá de las concentraciones a pie de calle. Se alcanza otro público)

Empleo de otras formas de comunicación (La apuesta comunicativa y divulgativa se diversifica, con propuestas como, la publicación de un periódico, la organización de exposiciones, mesas informativas, proyecciones audiovisuales, etc.)

Apuesta por el merchandising, que inunda las calles y los balcones (Se fabrican alrededor de 10.000 camisetas, 1.000 jerséis, 5.000 banderolas y miles de pegatinas. La presencia en la calle a través del merchandising es patente, y se contagia por los tres territorios históricos de la CAPV)

Consolidación de una portavocía preparada y eficaz (Se apuesta por formar a varias personas que sean capaces de dar charlas pueblo a pueblo. Así, la presencia en foros, charlas, debates, etc. se multiplica, con un mensaje claro y homogéneo)

Campañas de adhesión con el conjunto de representantes institucionales y políticos (El movimiento contra el fracking pide adhesiones políticas transversales formalmente. Consigue entrar en las campañas electorales y en la agenda de los políticos y de los representante públicos)

Campaña de mociones para declarar pueblos libres de fracking (Supone el primer peldaño de incidencia institucional. Las plataformas que conforman el movimiento presentan mociones en los municipios y previamente realizan un trabajo de sensibilización en la zona que acompaña a la moción. Las mociones sirven para trabajar y tener eco mediático a nivel local)

Presentación de una Iniciativa Legislativa Popular contra el fracking (Al margen de constituir la mayor apuesta institucional y jurídica del movimiento, se plantea como una gran movilización social por lo que suponen la recogida de un mínimo de 30.000 firmas. Finalmente se recogen 103.589 y se consigue aprobar la iniciativa sin ningún voto en contra. Se refuerza el trabajo de interlocución con los grupos políticos)

La construcción del discurso para oponerse al fracking (Consigue difundir lenguajes de valoración diferentes, apelando a argumentos generales que afectan a muchas capas de la sociedad, como, por ejemplo, la contaminación del agua. Se aprovecha también para profundizar en temas como el contexto y la dependencia energética)

Prontitud de la respuesta (El movimiento se empieza a organizar con rapidez, y responde con presteza a los diversos anuncios del Gobierno Vasco. En ocasiones, consigue anticiparse al discurso y a la acción de los favorables a la técnica)

Percepción del riesgo (Un método extractivo, a priori invasivo y de alto impacto medioambiental, desconocido en suelo vasco, despierta recelos y temor en la comunidad local. No se conocen otras experiencias cerca)

\subsection{La construcción del conflicto ambiental}

De los testimonios recopilados destacan dos aseveraciones comunes en todos o casi todos los entrevistados. Por un lado, el movimiento de oposición al fracking en la CAPV ha tenido un notable éxito, cuantificable al menos en la recogida de firmas para una Iniciativa Legislativa Popular. La influencia que ha tenido, además, atraviesa los distintos estamentos sociales, políticos e institucionales, y ha conseguido imponer su lenguaje de valoración. Lo explica gráficamente uno de los entrevistados (A1) diciendo que "la movilización social y la gran información repartida a la ciudadanía hizo que la opinión mayoritaria en la calle fuera contraria a la técnica y que nadie favorable a la fractura hidráulica quisiera dar la cara".

Por otro lado, otra de las reflexiones comunes se asienta en una referencia al contexto o momento en el que el fracking entra en la agenda institucional y mediática. Si aquel anuncio del Lehendakari, en octubre del 2011, de la apuesta por la extracción de 
hidrocarburos mediante fracking, se hubiera realizado con otros actores políticos con más apoyo social e institucional, y con más experiencia en la gestión institucional, si se hubiera hecho con una planificación más trabajada, con el contexto técnico y energético más detallado, con un timing más elaborado, etc. el resultado del movimiento contra el fracking podría haber sido otro (informantes A3, P7 y C10).

\subsubsection{El que da primero: La anticipación como elemento diferenciador}

La técnica del fracking, durante los primeros días en los que el término se ubicó en la agenda de los medios de comunicación, se relacionó mayoritariamente con algo "impactante", "ajeno", "amenazante", "invasivo", "conflictivo", "perjudicial", "contaminante", etc. Todos ellos términos de connotaciones negativas. Así lo percibían los participantes del movimiento: "Pensábamos que era una barbaridad y algo muy impactante técnicamente; en cierta manera, creíamos directamente que era una burrada" (I5).

Respecto al propio movimiento, brotaron palabras como "pedagógico", "plural”, "transparente", "creíble", "cualificado", "dinámico", “diverso", "heterogéneo", "antidesarrollista", "trabajador", "esforzado", "perseverante", "lobby", etc. La mayoría resultaron connotaciones positivas, con la única salvedad de algunos entrevistados que se cuestionaron si, en sus inicios, el movimiento estuvo o no politizado. Ambas perspectivas son resumidas por las siguientes declaraciones de los informantes I5 y $\mathrm{C} 10$, respectivamente: "Era gente heterogénea, plural. Un grupo de gente con formación e inquietudes medioambientales"; "Las plataformas, sobre todo durante los primeros meses, estaban muy vinculadas a un partido político, la izquierda abertzale [izquierda nacionalista vasca]... aunque también es cierto que tuvieron la capacidad de hablar con todo el mundo, sumar y pensar en el objetivo final".

Hubo coincidencia plena a la hora de calificar como "vacuo", "ineficaz" y "descoordinado" el conjunto de voces que quisieron defender el uso de la fractura hidráulica. Los periodistas entrevistados, acostumbrados a interrogar varias fuentes antes de publicar cualquier artículo, reconocieron que los interlocutores que debían defender la apuesta energética del Gobierno Vasco eran prácticamente inexistentes. A pesar de que durante las entrevistas se sugirieron interlocutores profracking como el propio Gobierno Vasco, el departamento de Industria, la Viceconsejería de Energía y Minas, los colegios de ingenieros, expertos del ámbito universitario, los responsables de SESHA (compañía vasca para la exploración y explotación de hidrocarburos), las empresas adjudicatarias de los permisos, etc., se concluye que "el antagonista del movimiento contra el fracking era prácticamente inexistente" (P7); "La parte favorable al fracking estaba totalmente callada. Ese fue el error principal, reconocido por ellos mismos, el no haber salido a hablar. Los medios necesitábamos fuentes y nos costaba muchísimo encontrar alguien que diera la cara", resume uno de los periodistas (P8).

\subsubsection{La improvisación institucional como ventaja}

La hipótesis de la mayoría de los entrevistados pasa por que el entonces Lehendakari, Patxi López (de viaje institucional en Estados Unidos), quiso contrarrestar el entusiasmo mediático que estaba generando la notificación 
de ETA $^{7}$ del alto el fuego con otro anuncio que pretendía revolucionar, en cierta manera, la agenda setting de los medios de comunicación. López ofreció durante su viaje a los medios todos los elementos necesarios para que su anuncio ocupara portadas y abriera informativos: fotografías, titulares, y expectativas ambiciosas impactantes.

Sin embargo, según se desprende del análisis de las entrevistas, el apasionamiento y la precipitación propició una respuesta de oposición ciudadana, política e institucional proporcional: "En política es importante medir las repercusiones de tus anuncios mediáticos y de tus acciones. Hay veces que agitas sin querer el avispero, como en este caso" (C9). Según los entrevistados, se generó incertidumbre, preocupación y sospecha hacia una técnica completamente ajena a la población vasca, y envuelta en controversia científica.

\subsubsection{La percepción de riesgo y el desarrollo del movimiento}

A partir del anuncio, algunas personas a título individual y algunos colectivos intranquilos por el anuncio se reunieron pocos días después de la noticia en un bar de Vitoria-Gasteiz (capital de Araba). Aquella reunión supuso el germen de la lucha ciudadana contra el fracking en tierras vascas. El movimiento de oposición, que tuvo su epicentro inicial en la capital alavesa, se expandió después por las comarcas del territorio y por las otras dos provincias de la CAPV, Bizkaia y Gipuzkoa, así como en Navarra, aunque en menor medida porque su nivel de afección era menor. Se habla de un "efecto Nymby expansivo" (I5) donde, lejos de tener connotaciones negativas, "la preocupación de las personas que se sienten afectadas es una herramienta muy potente para generar debate y concienciar a la gente planteando alternativas" (I6).

$\mathrm{Si}$ bien en sus inicios los grupos ecologistas participaron en la creación de las plataformas, éstas fueron consolidándose de forma autónoma, adquiriendo una identidad y funcionamiento propios. Así, en total se crearon en torno a 20 agrupaciones de ámbito local, comarcal o provincial de las cuales 13 tendrán una trayectoria, actividad y coordinación continuada (ver figura 1). La expansión de las plataformas coincide con las zonas donde los permisos de explotación se encuentran en una fase de licitación más avanzada, tal y como se demuestra en las figuras 2 y 3 . Así, en mayor medida se crean grupos en Álava y el oeste de Bizkaia.

7 La sociedad vasca esperaba un anuncio trascendental de la organización ETA declarando el final de su actividad armada, como así sucedió el 19 de octubre de 2011. Uno de los entrevistados, militante del partido político ecologista Equo, reconoce durante su entrevista que "nuestro partido era de los últimos en enterarse de estas cosas, y ya sabíamos que algo gordo iba a pasar" (I6). 


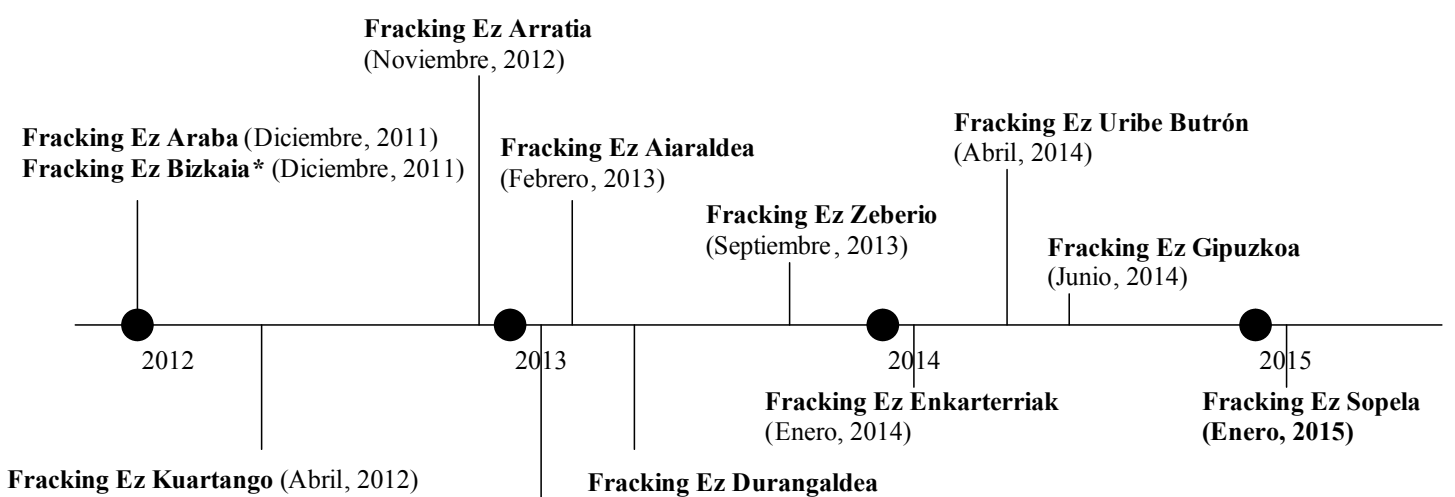

Fracking Ez Kuartango (Abril, 2012) Fracking Ez Mungialdea (Abril, 2012)

Fracking Ez Durangaldea (Abril, 2013)

Fracking Ez Getxo

(Enero, 2013)

FIGURA 1. EVOLUCIÓN TEMPORAL DE LA CREACIÓN DE LAS PLATAFORMAS CONTRA EL FRACKING EN LA CAPV (FUENTE: ELABORACIÓN PROPIA)

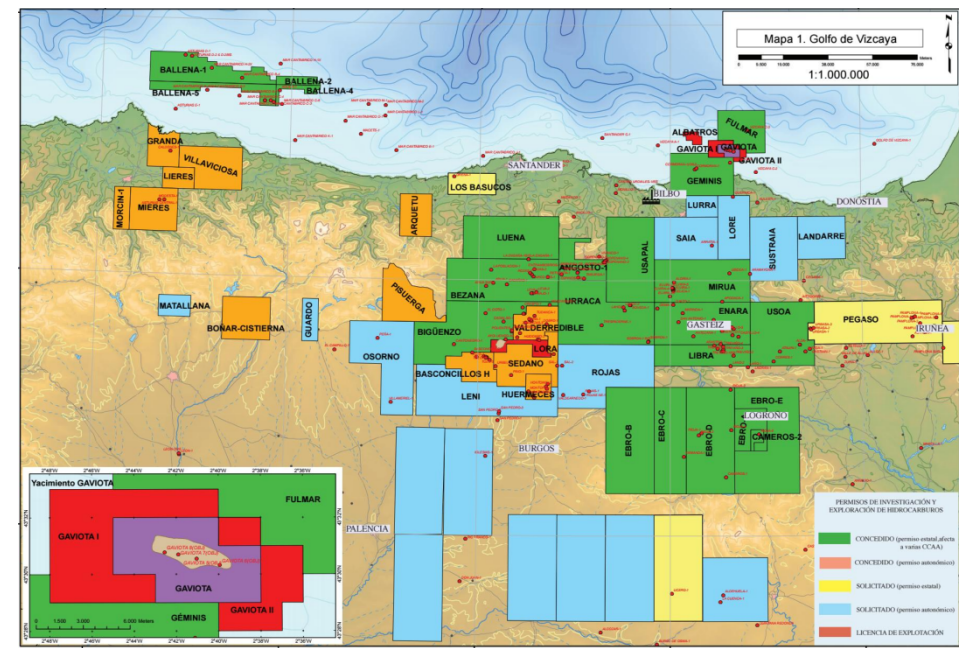

FIGURA 2. MAPA DE PERMISOS DE INVESTIGACIÓN Y EXPLORACIÓN EN LA CUENCA VASCOCANTÁBRICA (2016) (FUENTE: FRACKING EZ ARABA, 2012-B)

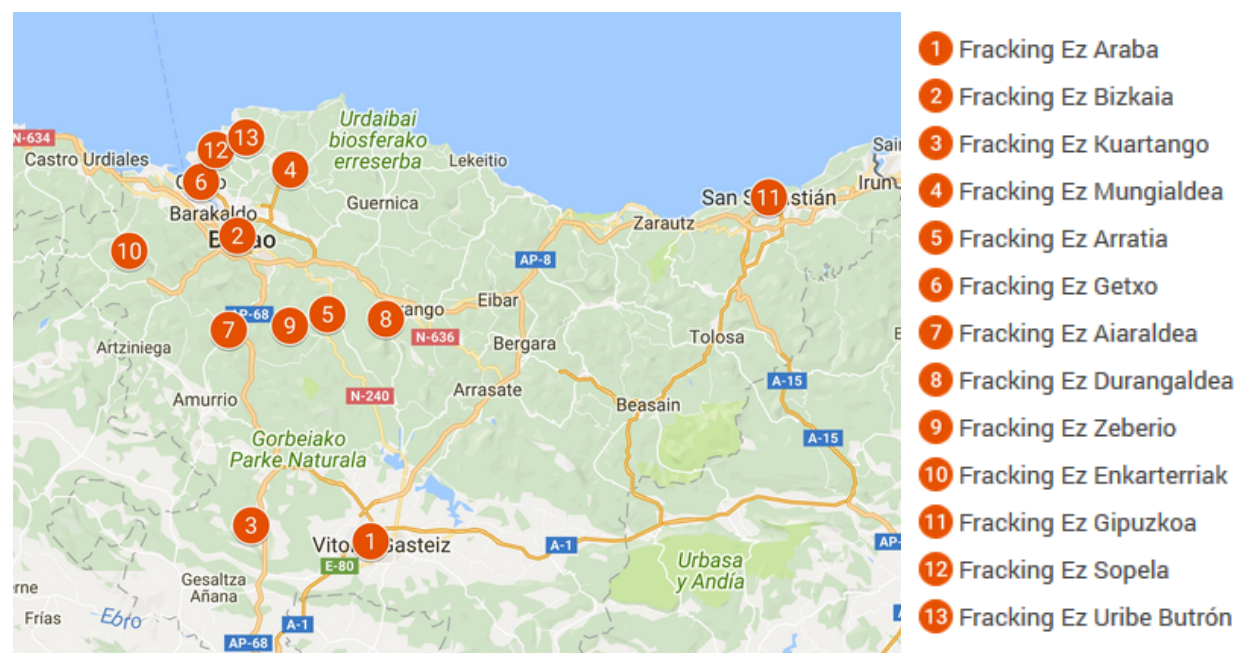

FIGURA 3. UBICACIÓN GEOGRÁFICA DE LAS PLATAFORMAS CONTRA EL FRACKING EN LA COMUNIDAD AUTÓNOMA DEL PAÍS VASCO (FUENTE: ELABORACIÓN PROPIA) 


\subsection{Los discursos y las estrategias movilizadoras}

En torno a la construcción del discurso, existe cierta disparidad en las lecturas aportadas por los entrevistados. Se diferencian dos grupos entre los participantes en el estudio: aquellos que participaron directamente en el movimiento, y quienes no lo hicieron.

Para el primer grupo (activistas), los principales argumentos que construyeron el relato de la lucha ciudadana contra el fracking se reparten en los siguientes bloques temáticos: contexto energético en el que surge el fracking, detalles sobre la técnica, riesgos ambientales y para la salud, contexto económico y aspectos económicos de la fractura hidráulica, situación de los planes de exploración, y la descripción de la movilización ciudadana (A1). Según los entrevistados que participaron directamente en el movimiento contra el fracking, los riesgos para la salud solo ocupaban una sexta parte de su argumentario en las charlas y conferencias que realizaron en pueblos y ciudades de la geografía vasca: "Hacíamos más hincapié en que era ruinoso económicamente, mal orientado respecto a la política energética y perjudicial para el medioambiente" (A1).

Sin embargo, según las consideraciones aportadas por el segundo grupo (periodistas, políticos, investigadores), los argumentos que más trascendieron a la opinión pública fueron, claramente, los relacionados con la salud. Junto a ello, otros conceptos como el imperialismo (empresas extranjeras que se aprovechan de los recursos propios) o la necesidad de proteger el entorno natural y las actividades económicas, también tuvieron presencia. El argumento imperialista penetró más, aparentemente, en capas ideologizadas; el de la protección del entorno natural en una parte de la sociedad más urbana; y el de las actividades económicas en la gente rural, que depende directamente de los recursos hídricos y naturales (I6). Sin embargo, la contaminación del agua, la importancia de los acuíferos, y su peligro de contaminación en caso de perforar a través del fracking, fueron las imágenes gráficas que se le quedaron grabadas a gran parte de la sociedad.

\subsubsection{La batalla de la información}

Uno de los principales recursos que emplearon los defensores de la fractura hidráulica fue advertir a la población de que las plataformas de oposición tenían la estrategia de crear una alarma social infundada. En torno a esta cuestión se infiere que, efectivamente, existía cierta percepción de riesgo en torno al fracking. Sin embargo, los miembros de la plataforma y los investigadores en este ámbito niegan que la alarma social fuera conscientemente y estratégicamente fomentada por las plataformas de oposición. Es decir, el propio anuncio del Gobierno Vasco y la escasa información trasladada a la ciudadanía pudo aumentar la percepción de riesgo.

De hecho, según la experiencia vivida por los activistas, fueron las plataformas de oposición quienes facilitaron información concreta sobre la situación de los permisos de perforación y la propia técnica, así como del contexto energético a personas directamente afectadas. En muchos casos, los propietarios de tierras se enteraron, incluso, por los opositores a la técnica, de que sus terrenos se veían afectados por los permisos solicitados. En otros casos, fueron miembros de la plataforma quienes tranquilizaron a parte de la población que creía que la mera aparición de técnicos, ingenieros o camiones en ciertas tareas ajenas a esta técnica suponía la llegada del fracking a sus municipios.

El movimiento contra el fracking, pues, explicó pueblo a pueblo la situación de los permisos (con los planes, estudios y las 
evaluaciones de impacto ambiental en mano), los riesgos de la técnica y cómo podían discernir entre lo que eran y lo que no eran los indicios de que el fracking podía llegar a cada zona. Asimismo, evitaron fotos catastrofistas descontextualizadas, para, precisamente, huir del fomento gratuito de la alarma social que no se consideró una estrategia de lucha eficaz (informante A1). Tal y como responden la mayoría de entrevistados, los promotores de la iniciativa extractiva, sin embargo, pudieron haber llevado a cabo una deficiente política de comunicación, dejando más espacio a la opacidad que a la transparencia, por las urgencias y necesidades comunicativas. Así, "las contradicciones y las incoherencias en los mensajes de los promotores no ayudaron a posicionar a la opinión pública y a la opinión publicada a favor de la fractura" (P8).

La batalla para establecer los "datos reales" acerca de la identificación de riesgos, que hemos señalado suele ser un rasgo común en los debates entre grupos ecologistas, organismos oficiales, y empresas y grupos de presión, se decanta en este caso a favor del movimiento antifracking, que adopta el diálogo técnico, y establece una ciencia posnormal, contra-hegemónica, basada en la evaluación ampliada a los no expertos oficiales. El propio activismo, pues, se convierte en una fuente importante de conocimiento y el propio movimiento aprende también el vocabulario que necesita. Varios de los integrantes de las plataformas contra el fracking fueron quienes aprendieron con detalle cuestiones relacionadas con la técnica, estudiaron detenidamente el estado de los permisos, analizaron sesudamente los estudios de evaluación de impacto ambiental, etc.

\subsubsection{Los lenguajes de valoración}

El movimiento no renuncia a la disputa en el propio marco de las lógicas autorizadas $\mathrm{y}$ legitimadas, especialmente en el lenguaje de valoración económico. Además, es capaz de modular el discurso según el interlocutor, de forma que las referencias económicas apelan de diferente manera en un receptor rural que en un receptor urbano.

Así, en el primer caso, frente a los defensores de la técnica, que por ejemplo aluden a la posibilidad de puestos de trabajo en las zonas rurales, las plataformas contra el fracking anteponen la defensa de la forma actual de ganarse la vida en tales zonas, que podría ponerse en riesgo. Por otro lado, para el receptor de tipo urbano se pulsan otros imaginarios, como el del despilfarro económico, que detraerá dinero público que podría destinarse a otras necesidades, al tiempo que apela a que no solucionaría la dependencia energética (informantes A1, I5 e I6).

Pero, como hemos señalado, la producción de conocimiento ambiental no es sólo una cuestión científica, sino también política. La construcción de un discurso contrahegemónico trabaja, en efecto, la disputa en el seno de las mismas lógicas de la realidad construida por la ciencia corporativa, planteando los impactos ambientales, sociales y económicos en los lenguajes de valoración autorizados y legitimados, con un uso alternativo. Pero al tiempo, gran parte de su potencial éxito contra-hegemónico reside en la capacidad de movilizar e incorporar también otros lenguajes de valoración alternativos.

Así, junto a la disputa del lenguaje de valoración económico, el movimiento despliega otros lenguajes de valoración medioambientales y de salud, de valoración de riesgos e impactos ambientales, como el de la potencial contaminación de los acuíferos y el agua. Y tratan de situar ahí también evidencias científicas. Y de diversificar la percepción de 
los posibles riesgos en función de diferentes receptores potenciales. El discurso se dirige, pues, al agricultor que ve cómo la calidad de sus cultivos depende del agua de riego, al ganadero que ve cómo sus pastos pueden recibir agua de ríos contaminados por los elementos químicos que emplea el fracking, al receptor urbano que se preocupa por la calidad del agua que bebe... (informante A3).

\subsubsection{Fracking para nadie: la justicia ambiental y transición ecológica}

La oposición contra el fracking en tierras vascas se activa por la percepción de riesgo para las comunidades y medioambiente locales, pero el discurso desarrolla elementos globales de crítica y desconfianza hacia ese desarrollo técnico, apuntando que el fracking es una técnica prescindible en cualquier territorio del mundo. De hecho, así se recoge en el lema transversal que atraviesa los más de cinco años de su actividad: "Fracking ez, ez hemen ez inon" ("Fracking no, ni aquí ni en ningún sitio").

Además, tal y como hace hincapié el bloque de los informantes que participaron activamente en los movimientos, el trabajo de las plataformas va unido a una contextualización de la situación energética, a una concienciación sobre la necesidad de cambiar a otro modelo energético, prescindiendo de los recursos energéticos fósiles, y a una referencia solidaria a luchas similares en otras partes del mundo, alimentando posturas de solidaridad con otros movimientos. Lejos de un efecto NIMBY estaríamos ante una caracterización que algunos autores como de Uribe y Pascual (2013) catalogan como NIABY, esto es, not in anybody's back yard (no en el patio trasero de nadie). Es decir, los miembros del movimiento no quieren que se emplee el fracking ni en frente de su casa ni en ningún sitio, y así lo explican en el trabajo de concienciación social que alimenta la movilización social.

En general, se emplea un lenguaje de crítica del modelo de desarrollo, y de desconfianza ante el riesgo de determinados avances técnicos, que lo sitúa en el campo de los movimientos por la justicia ambiental y en las versiones críticas con el desarrollo sostenible, e incluso cercano a las reflexiones decrecentistas y de transición ecológica.

\subsubsection{La movilización social}

Los principales hitos o hechos trasversales que hemos recopilado dibujan un aumento gradual en la repercusión, a través de la capacidad de movilización social. Es decir, se recurre a la movilización social, convencidos de que ésta repercutirá en los medios de comunicación y en el ámbito político e institucional: "Dinamismo y presión en la calle para influir en lo social y en lo político", resume uno de los entrevistados (informante A1).

Podríamos diferenciar tres etapas en este apartado: los inicios del movimiento contra el fracking, su consolidación y su cenit. En el primero de ellos, ubicamos movilizaciones modestas como campañas de alegaciones contra ciertas decisiones institucionales (primera campaña de alegaciones Enara-4, 
octubre de 2012) $)^{8}$, o concentraciones que reúnen a algunas decenas de personas.

La consolidación del movimiento comienza con la diversificación de las propias movilizaciones, organizando, por ejemplo, marchas montañeras ${ }^{9}$, o distintos eventos sociales/deportivos bajo el lema de Fracking Ez (Fracking No). En estas citas se consigue reunir un mayor número de personas, y se diversifica el tipo de convocante. Sin embargo, su verdadera consolidación llega con la masiva manifestación celebrada en octubre de 2012, donde se reúnen 13000 personas llegadas desde Araba y los territorios aledaños ${ }^{10}$. Es una de las mayores manifestaciones en este ámbito a nivel mundial. La convocatoria supera las expectativas de los organizadores, que deciden continuar por el mismo camino.

La herramienta que da paso al cenit del movimiento es la Iniciativa Legislativa Popular (ILP) para prohibir el fracking ("Proposición de Ley de medidas adicionales de protección medioambiental para la extracción de hidrocarburos no convencionales y la fractura hidráulica o fracking") ${ }^{11}$.

Así, no solo se plantea la posibilidad de explorar el techo institucional, convirtiéndose el movimiento en un sujeto que impulsa legislar; la ILP se diseña para superar la marca obtenida durante la manifestación y conseguir la adhesión de más personas a esta reivindicación (informantes A1, A3 y A4). El plan tampoco defrauda: 103589 firmas válidas (sobre una población total de $2 \quad 164311$ habitantes en 2015) se posicionan contra el fracking y se muestran favorables de prohibirlo en la CAPV. La ILP, pues, constituye el momento culmen de un movimiento maduro, que conquista techos insólitos (tanto legislativos como de movilización social) para una lucha ciudadana del ámbito ecologista.

Todo ello viene reforzado, además, por una importante apuesta por el merchandising al que se refieren los entrevistados. No se vincula únicamente a la venta en sí de material, que servirá, a la postre, para financiar las acciones de los colectivos; el merchandising significa convertir la expresión visual de la lucha social en algo duradero (informante A4). La proliferación de camisetas, pegatinas $\mathrm{y}$ banderas con los lemas y las reivindicaciones de la plataforma hicieron que su presencia en la sociedad fuera continua $y$ en ascenso. Se considera así que este elemento forma parte de la movilización social.

\section{Discusión y conclusiones}

En las tierras vascas ha habido numerosas reivindicaciones medioambientales. No obstante, los casos más conocidos, debido, entre otros, a las enérgicas protestas ciudadanas, han sido los casos de la Central Nuclear de Lemoiz, la construcción de la A-15

8 Más información en "Presentan más de 600 alegaciones contra un tercer pozo de gas en Álava" (Europa Press), disponible en https://cutt.ly/Fu6RPNn

9 Más información sobre actividades de ocio y deportivas de carácter reivindicativo en Naiz.eus (https://cutt.ly/bu6TT4w); Elcorreo.com (https://cutt.ly/Ju6TJsG); Elpais.com (https://cutt.ly/ Eu6T8op).

10 Más información en "Una multitud protesta contra el fracking en Vitoria" (Elcorreo.com), disponible en https://cutt.ly/nu6YHRf

11 Más información en "Más de 103.500 firmas piden prohibir el fracking en Euskadi” (El Mundo), disponible en https://cutt.ly/4u6Usxv; y en "103.589 firmas contra el fracking: ¿Y ahora qué?" (eldiario.es), disponible en https://cutt.ly/8u6UmGT 
(Autovía de Leizarán), la Y vasca (tren de alta velocidad) y la técnica de la extracción de hidrocarburos mediante fractura hidráulica (fracking).

La forma adoptada tradicionalmente por la práctica crítica del ecologismo vasco ha sido en su mayoría la de manifestaciones, y además con un alto grado de confrontación, debido a la falta de comunicación y de "puentes" entre los interlocutores (Bárcena, 2000). A ello no es ajeno el propio contexto sociopolítico vasco, fuertemente polarizado y confrontativo, y atravesado por la realidad traumática de las violencias, que afectan también de lleno a los movimientos ecologistas.

En ese sentido, el movimiento ciudadano contra el fracking coincide con la apertura de un nuevo ciclo político, caracterizado por una mayor distensión tras el final de la actividad armada de ETA. De forma que podemos registrar un cierto viraje en la práctica crítica del ecologismo vasco: centra su acción en disputa de la evidencia científica, el diálogo técnico, la creación del relato, la distribución de información, la colaboración y búsqueda de alianzas, y la diversificación de los métodos de protesta y de manifestación.

Todos estos elementos estaban también presentes en conflictos anteriores, sobre todo en la denuncia de los impactos ambientales, pero incluso en la interlocución y acuerdo con las instituciones en el caso de la autovía de Leizarán. Sin embargo, podemos observar que se tornan centrales en el caso del movimiento contra el fracking, de una forma más explícita y menos confrontativa, y que tanto sus protagonistas directos como quienes lo siguen de cerca lo sitúan como una característica central, una seña de identidad. El movimiento construye una clara estrategia de disputa de la hegemonía científica y comunicativa.

Y a partir del relativo éxito movilizador, comunicativo y político del movimiento, el presente estudio nos permite profundizar también en torno a los procesos de lucha ecológica en los que la disputa científica y comunicativa juega un valor central.

En primer lugar, ha de reiterarse en este caso la importancia de las estructuras de oportunidad política. Ya hemos mencionado el cambio de contexto político general, que facilita la construcción de estrategias no tan confrontativas y polarizadas, y sin traumáticas injerencias externas. Pero en particular, en este caso el movimiento muestra una reseñable capacidad para aprovechar la oportunidad política abierta por el anuncio oficial en torno al fracking, anticipándose a las construcciones de ciencia corporativa, y convirtiendo en una oportunidad y fortaleza la alarma social generada. Así, la rápida reacción y organización del movimiento resultan claves para situarse en la habitual disputa sobre la evidencia científica, característica de los conflictos ambientales.

Como segunda reflexión, hemos de señalar que el movimiento consigue así coproducir procesos sociales y culturales de percepción de riesgos y de conocimiento científico. Hace efectiva esa ciencia ampliada al activismo: las y los participantes en el movimiento aprenden el vocabulario que necesitan, y el activismo se convierte también en una fuente de conocimiento. Se consigue así utilizar los conocimientos científicos dominantes desde una práctica activista contrahegemónica. Pero la construcción del discurso desempeñada por sus portavoces no se limita a la disputa de los datos científicos y económicos utilizando las lógicas legitimadas desde una práctica contra-hegemónica, también moviliza lenguajes de valoración alternativos en base a argumentos medioambientales y de salud, no limitando su argumentario a la alarma social.

Todo ello permite a los movimientos ganar en visibilidad y legitimidad. E1 
movimiento contra el fracking se convierte así en una voz autorizada, legítima y eficaz para sensibilizar a la ciudadanía, así como para influir social, mediática y políticamente, en una sociedad preocupada y necesitada de respuestas, y ante unos partidos políticos que requerían fijar su postura respecto al fracking.

La tercera reflexión nos lleva a que la disputa científica y la construcción del discurso y de la percepción del conflicto es, como hemos visto, importante, pero para un movimiento social va en relación al activismo práctico. Es esa combinación la que posibilita al movimiento construir los procesos sociales y culturales de percepción del conflicto ambiental. En este caso, "Fracking Ez Araba", punta de lanza del movimiento contra el fracking en la CAPV, recurre también a la movilización social para conseguir sus objetivos. Con un timing construido a medida que llegan los diversos hitos, la movilización social dibuja un escenario in crescendo: comienza con pequeñas movilizaciones, organiza una manifestación multitudinaria, y culmina con la elaboración y aprobación de la Iniciativa Legislativa Popular para prohibir el fracking.

A partir de todo esto podemos reseñar una última reflexión acerca de las posibilidades y límites de los discursos y prácticas ecologistas. En efecto, un debate recurrente en estos casos atañe a que la movilización ambiental es más sencilla en contextos locales y ante la percepción de riesgos, pero sin embargo resulta más complicada de articular cuando se refiere a consideraciones de carácter más sistémico y generalista, como el caso de las propuestas de transición ecológica o el decrecimiento. Algunas movilizaciones internacionales recientes como Fridays for Future o Extinction Rebellion han mostrado, sin embargo, una reseñable capacidad para movilizar - especialmente a jóvenes - en base a la crisis ecológica global y sistémica y la reivindicación de cambio y un futuro distinto, en una suerte de rebelión ante la posibilidad del colapso civilizatorio.

En el caso que nos ocupa, el movimiento contra el fracking no ha planteado las reivindicaciones como un objetivo local $y$ particular, sino que también ofrece alternativas para resolver de otra manera los problemas del territorio, y discute el modelo de sociedad y economía implícito en las actuaciones que rechaza. Aunque es cierto que esos discursos han declinado al detenerse la cuestión concreta y local del fracking, lo es también que tal cuestionamiento general del modelo de desarrollo ha estado presente. Es más, el rechazo al fracking supone, de hecho, el rechazo a las salidas tecno-científicas "mágicas" a la crisis energética de los combustibles fósiles ("la tecnología nos salvará"), frente a la que antepone con relativo éxito otras lógicas y leguajes de valoración como la salud y la sostenibilidad -en sus acepciones más críticas- al tiempo que cuestiona el modelo de desarrollo.

En suma, los resultados resultan aplicables a conflictos socio-ecológicos parecidos en los que la población reacciona y paraliza actuaciones en contra del territorio y de los humanos de hoy y mañana, y hace frente a los intereses de las grandes corporaciones, multinacionales y gobiernos. Y muestra que es la combinación de las estructuras de oportunidad política, los diferentes lenguajes de valoración y la construcción de ciencia contra-hegemónica, la movilización social diversificada e innovación táctica, y la inserción de los objetivos locales en una lógica ecológica más general, la que permite construir mayorías sociales y hegemonía sociocultural. 


\section{Referencias Bibliográficas}

Alonso, Luis Enrique (2013). La sociohermenéutica como programa de investigación en sociología. ARBOR, Ciencia, Pensamiento y Cultura, 189 (761), pp. 189-761. DOI: http:// dx.doi.org/10.3989/arbor.2013.761n3003

Ayllón, Juan Manuel (2014). El agua, sin gas, por favor: la controversia jurídica en torno al fracking en España. EXtoikos, 15, pp. 35-44.

Azkarraga, Joseba. (2017). Trantsizio ekosoziala helburu: ondo bizi, denok, muga biofisikoen barruan. Hegoak zabalduz, 5. Bilbao: Hegoa, UPV/EHU.

Bárcena, Iñaki. (2000). Los dilemas de la ecología vasca. Euskonews, Eusko Ikaskuntza. Disponible en: http://www.euskonews.com/0083zbk/gaia8301es.html.

Bauman, Zigmun. (1999). Modernidad líquida. Buenos Aires: Fondo de Cultura Económica.

Beck, Ulrick. (2002). La sociedad del riesgo. Hacia una nueva modernidad. Barcelona: Ediciones Paidós Ibérica S.A.

Buttel, Frederick (2002). Instituciones sociales y cambio medioambiental. En M. Redclift y G. Woodgate (Eds.), Sociología del medio ambiente. Una perspectiva internacional (pp. 27-44). Madrid: McGraw-Hill.

Caballero, Manuela (2015). Transferencias ambientales intergeneracionales: un análisis sobre abuelos y nietos [Tesis doctoral]. Universidad Pontificia de Salamanca.

Caballero, Manuela (2017). Spanish Environmental Generations in the Twentieth Century. Human Ecology Review, 23(1), 3-22. DOI: https://doi.org/10.22459/HER.23.01.2017.01

Carson, Rachel (1962). Silent Pring. Boston: Houghton Mifflin.

Castells, Manuel (1997). La era de la información. Economía, sociedad y cultura. El poder de la identidad. Vol. 2. México: Siglo XXI editores.

Catton, William R., Dunlap, Riley E. (1978). Paradigms, Theories and the Primacy of the HEP-NEP Distinction. The American Sociologist, 13, 256-259.

Cingotti, Natacha (2014). Fracking: un pozo sin fondo. Dossier Informativo, marzo de 2014.

Comisión Europea (2014). Comunicación sobre la exploración y producción de hidrocarburos (como el gas de esquisto) utilizando la fracturación hidráulica de alto volumen en la UE, COM(2014) 23 final, 22 de enero de 2014 p. 6. Disponible en: http://eur-lex.europa.eu/legalcontent/ES/TXT/PDF/?uri=CELEX:52014DC0023\&from=ES

Conde, Marta (2014). Activism mobilising science. Ecological Economics, 105, 67-77. DOI: https://doi.org/10.1016/j.ecolecon.2014.05.012

Del Amo, Ion Andoni y Arkaitz Letamendia (2020). Las transformaciones postcrisis. Movilizaciones espasmódicas y Gran Evento. Foro Interno, Anuario de teoría política, 20 [en prensa].

Demaria, Federico, François Schneider, Filka Sekulova y Joan Martínez-Alier (2013). What is degrowth? From an activist slogan to a social movement. Environmental Values, 22 (2), 191-215. DOI: https://doi.org/10.3197/096327113X13581561725194

Dunlap, Riley (2002). Evolución de la sociología del medio ambiente: Breve historia y valoración de la experiencia estadounidense. En M. Redclift y G. Woodgate (Eds.), Sociología del medio ambiente. Una perspectiva internacional (pp. 3-26). Madrid: McGraw-Hill. 
Eisenhardt, Kathleen (1989): Building theories from case study research. Academy of Management Review, 14(4), 532-550. DOI: https://doi.org/10.5465/amr.1989.4308385

Ecyt-Ar (2013). Hidrocarburo no convencional. Enciclopedia de ciencias y tecnologías en argentina. Disponible en: http://cyt-ar.com.ar/cyt-ar/index.php/Hidrocarburo_no_convencional

Flues, Fabian (2013). A slow costly road to nowhere: shale gas development in Europe. Friends of the Earth Europe. Disponible en: http://www.foeeurope.org/sites/default/files/ foee_slow_and_costly_road_may2013.pdf

Fracking Ez Araba (2012a). Araba: Un intenso arranque dedicado a parar el fracking. En Fracking Ez Araba (Ed.), Fracking, una apuesta peligrosa (pp. 99-102). Vitoria-Gasteiz.

Fracking Ez Araba (2012b). Estado de la cuestión: ¿Dónde se hace fracking? En Fracking Ez Araba (Ed.), Fracking, una apuesta peligrosa (pp. 21-27). Vitoria-Gasteiz.

Fracking Ez Araba (2012c). Oponiéndose al fracking: Movimientos resonantes. En Fracking Ez Araba (Ed.), Fracking, una apuesta peligrosa (pp. 90-93). Vitoria-Gasteiz.

García, Ernest (2004). Medio Ambiente y Sociedad. La civilización industrial y los límites del planeta. Madrid: Alianza Editorial.

García, Ernes (2006). El cambio social más allá de los límites al crecimiento: un nuevo referente para el realismo en la sociología ecológica. Aposta Revista de CienciasSociales, 27. DOI: http://dx.doi.org/10.5565/rev/papers/v82n0.2055

Giddens, Anthony (1996). Modernidad y autoidentidad. En J. J. Beriain (Ed.), Las consecuencias perversas de la modernidad (pp. 33-72). Barcelona: Anthropos.

Giddens, Anthony (1997). Modernidad e identidad del yo. El yo y la sociedad en la época contemporánea. Barcelona: Península.

Grønhøj, Alice y John Thøgersen (2009). Like father, like son. Intergenerational transmission of values, attitudes and behaviours in the environmental domain. Journal os Environmental Psichology, 29, 414-421. DOI: https://doi.org/10.1016/j.jenvp.2009.05.002

Heras, Iñaki, Ibon Zamanillo e Iker Laskurain (2013). Social acceptance of ocean wave energy: A case study of an OWC shoreline plant. Renewable and Sustainable Energy Reviews 27, 515-524. DOI: https://doi.org/10.1016/j.rser.2013.07.032

Herce, Iñigo (2014). La batalla del fracking. www.eitb.eus. Disponible en: https:// www.eitb.eus/es/noticias/detalle/2817628/fracking-euskadi-analisis-debate-fractura-hidraulica-/ [Consultado en junio 2020]

Hoyos, David (2020, 22 de junio). Segundo varapalo del Tribunal de Cuentas Europeo a la Y vasca. Diario Gara. Disponible en: https://www.naiz.eus/es/iritzia/articulos/segundo-varapalo-deltribunal-de-cuentas-europeo-a-la-y-vasca

Inglehart, Ronald (1977). The Silent Revolution. Princeton: Princeton University Press.

Irwin, Alan (2002). Riesgo, medio ambiente y conocimientos medioambientales. En M. Redclift y G. Woodgate (Eds.), Sociología del medio ambiente. Una perspectiva internacional (pp. 63-76). Madrid: McGraw-Hill.

Janicke, Martin (1986). State Failure: The Impotence of Politics in Industrial Society. Cambridge: Polity Press.

Kirsch, Stuart (2014). Mining capitalism: The relationship between corporations and their critics. Oakland: University of California Press. 
Latour, Bruno (1999). Pandora's HopeEssays on the Reality of Science Studies. Cambridge: Harvard University Press.

Latour, Bruno (2007). Nunca fuimos modernos. Ensayo de antropología simétrica. Madrid: Siglo XXI.

Law, John (2004). After Method: Mess in Social Science Research. London: Routledge.

Law, John (2011). What's wrong with a one-world world? HeterogeneitiesDOTnet. Disponible en: http://www.heterogeneities.net/publications/ Law2011WhatsWrongWithAOneWorldWorld.pdf

Letamendia, Arkaitz, Ion Andoni del Amo y Jason Diaux (2014). Audiovisual cultural artifacts of protest in the Basque country. Pacific Journalism Review, 20(2), 224-240. DOI: https:// doi.org/10.24135/pjr.v20i2.175

López-Martínez, Mario (2015). Nonviolence in social sciences: towards a consensual definition. Revista de paz y conflictos, 8(1), 63-81.

Martín-Sosa, Samuel. (2015). Cronología e instantánea de la resistencia. En Ecologístas en Acción (Ed.), Resistencia global al fracking. El despertar ciudadano ante la crisis climática y democrática (pp. 11-24). Madrid.

Martínez-Alier, Joan (2009). El Ecologismo de los Pobres. Conflictos Ambientales y Lenguajes de Valoración. Barcelona: Icaria.

Martinez-Alier, Joan et al. (2014). Between activism and science: grassroots concepts for sustainability coined by Environmental Justice Organizations. Journal of Political Ecology, 21,19-60. DOI: https://doi.org/10.2458/v21i1.21124

Meadows, Donella. H., Dennis L. Meadows, Jorgen Randers y William WBehrens (1972). The Limits to Growth. Washington, DC: Universe Books.

Mol, Arthur (2002). Modernizacion ecológica: transformaciones industriales y reforma medioambiental. En M. Redclift, y G. Woodgate (Eds.), Sociología del medio ambiente. Una perspectiva internacional (pp. 143-156). Madrid: McGraw Hill.

Morin, Edgar (1974). La nature de la société. Communication, 22, 3-32. DOI: https://doi.org/ $\underline{10.3406 / \mathrm{comm} .1974 .1335}$

Offe, Claus (1996). Partidos políticos y nuevos movimientos sociales. Madrid: Sistema.

Riechmann, Jorge y Francisco Fernández. (1994). Redes que dan libertad. Introducción a los nuevos movimientos sociales. Barcelona: Paidós.

Riechmann, Jorge (2015). Autoconstrucción. Ensayos sobre la transformación cultural que necesitamos. Madrid: Los Libros de la Catarata.

Sachs, Wolfgang. (2002). Desarrollo sostenible. En M. Redclift y G. Woodgate (Eds.), Sociología del medio ambiente. Una perspectiva internacional (pp. 63-76). Madrid: McGraw-Hill.

Sánchez-Vázquez, Luis (2019). ¿Ciencia de resistencia? Monitoreos ambientales participativos en contextos de conflicto ambiental. Reflexiones desde una mirada decolonial. Revista de Paz y Conflictos, 12 (2), 57-79. DOI: https://doi.org/10.30827/revpaz.v12i2.10399

Sández, Juan Diego (2014). La fracturación hidráulica en la Unión Europea: Estado de la cuestión. Instituto Español de Estudios Estratégicos.

Santamaría, Ainara, Edorta Arana y Ion Andoni del Amo (2019). Arrasaten komunitatea(k) ehunduz. En O. Arbelaitz, U. Etxeberria, A. Latatu, y M. J. Omaetxebarria (Eds.), III. Ikergazte. 
Nazioarteko ikerketa euskaraz. Kongresuko artikulu bilduma. Gizarte Zientziak eta Zuzenbidea (pp. 122-130). Bilbao: Udako Euskal Unibertsitatea (UEU).

Santos, Boaventura de Sousa (2017). Justicia entre saberes. Epistemologías del Sur contra el epistemicidio. Madrid: Morata.

Santos, Boaventura De Sousa y Paula Meneses (Eds.) (2014). Epistemologías del sur (Perspectivas). Madrid: Akal.

Spaargaren, Gert, y Arthur Mol. (1991). Sociology, Environment and Modernity: Ecological Modernisations as a Theory of Social Change. Wageningen: LUW.

Taibo, Carlos (2014). ¿Por qué el decrecimiento? Un ensayo sobre la antesala del colapso. Barcelona: Los Libros del Lince.

Temper, Leah, Federico Demaria, Arnim Scheidel, Daniela Del Bene \& Joan Martinez-Alier (2018). The Global Environmental Justice Atlas (EJAtlas): ecological distribution conflicts as forces for sustainability. Sustain Sci, 13, 573-584. DOI: https://doi.org/10.1007/s11625-018-0563-4

Uribe, Clara y Jordi Pascual i Martí (2013). Los nimbys como generadores de situaciones de crisis. Más poder local. Especial. Comunicación gubernamental, 1-12.

Urresti, Aitor (2012). ¿Por qué en Araba? En Fracking Ez Araba (Ed.), Fracking, una apuesta peligrosa (pp. 78-81). Vitoria-Gasteiz.

Urresti, Aitor y Florent Marcellesi (2012). Fracking: una fractura que pasará factura. Ecología Política, 43, 23-36.

Wood, Jonathan (2012). The global anti-fracking movement what it wants, how it operates and what's next. London: Control Risks.

Woodgate, Graham. (2002). Introducción. En M. Redclift y G. Woodgate (Eds.), Sociología del medio ambiente. Una perspectiva internacional (pp. xv-xxxii). Madrid: McGraw-Hill.

Yearley, Steven (2002). Ciencia y medio ambiente. En M. Redclift y G. Woodgate (Eds.), Sociología del medio ambiente. Una perspectiva internacional (pp. 235-246). Madrid: McGrawHill.

Yin, Robert K. (1998). The abridged version of case study research: Desing and method. En L. Bickman, D.J. Rog. (Eds.), Handbook of applied social research methods (pp. 229-259). Thousand Oaks: Sage publications.

\author{
PROCESO EDITORIAL • EDITORIAL PROCESS INFO \\ Recibido: $15 / 04 / 2020 \quad$ Aceptado: 02/07/2020
}

\title{
CÓMO CITAR ESTE ARTÍ́CULO $•$ HOW TO CITE THIS PAPER
}

Orbegozo Terradillos, Julen; del Amo Castro, Ion Andoni; Zarrabeitia Bilbao, Enara (2020). El movimiento antifracking en tierras vascas: relato, movilización y disputa de la evidencia científica. Revista de Paz y Conflictos, Vol.13 (1), 203-232.

\section{SOBRE LOS AUTORES • ABOUT THE AUTHORS}

Julen Orbegozo Terradillos es Licenciado en Publicidad y Relaciones Públicas y Periodismo. Profesor del departamento de Comunicación Audiovisual y Publicidad de la Facultad de Ciencias Sociales y de la Comunicación de la Universidad del País Vasco. Profesor de Dirección de la Comunicación Pública y Comunicación Interpersonal. Ion Andoni del Amo Castro es Ingeniero superior de telecomunicaciones. Licenciado en sociología. Máster en modelos y áreas de investigación en ciencias sociales. Doctor en Comunicación Social. Profesor en la facultad de educación de Bilbao. Departamento de Teoría e Historia de la Educación.

Enara Zarrabeitia Bilbao es Ingeniera en Organización de Empresas. Doctora por la Universidad del País Vasco. Profesora adjunta del departamento de Organización de Empresas. 